\title{
Future prospects for palm oil refining and modifications
}

\author{
Véronique GIBON \\ José Vila AYALA \\ Peggy DIJCKMANS \\ Jeroen MAES \\ Wim DE GREYT
}

Desmet Ballestra Group, Minervastraat 1, B-1930 Zaventem, Belgium

<GIV@desmetballestra.com>

\begin{abstract}
Palm oil is rich in minor components that impart unique nutritional properties and need to be preserved. In this context, refining technologies have been improved, with the dual temperature deodorizer, the double condensing unit and the ice condensing system. The DOBI is a good tool to assess quality of the crude palm oil and its ability to be properly refined. Specially refined oils open a market for new high quality products (golden palm oil, red palm oil, white soaps, etc.). Palm oil is a good candidate for the multi-step dry fractionation process, aiming to the production of commodity oils and specialty fats (cocoa butter replacers). New technological developments allow quality and yield improvements. Palm oil and fractions are also valuable feedstock for enzymatic interesterification in which applications are for commodity oil (low-trans margarines and shortenings) and for special products (cocoa butter equivalents, infant formulation, ...).
\end{abstract}

Key words: palm oil, refining, dry fractionation, enzymatic interesterification

without affecting the quality of the refined palm oil is an important challenge. The physical refining can offer important advantages like higher oil yield, reduction of the use of chemicals, reduction of water and effluent and hence considerable improvement of the environmental impact. Nevertheless, the final choice between physical or chemical routes will depend on a number of factors: the quality and the acidity of the crude oil, the ability to get rid of the soapstocks and local legislation. For crude palm oil with low phosphatides, high initial acidity and high carotenoid content, physical refining is preferred in terms of operating costs and refining losses.

Most of natural oils have only a limited application in their original form, as a consequence of their specific chemical composition. They therefore often undergo a chemical or physical modification. Quite a number of questions arise with respect to the effect of the chemical modification processes on the nutritional quality of oils. The issue whether trans fatty acids have a negative impact on health also forces producers to find alternatives like dry fractionation and enzymatic interesterification. Due to the continuous technological developments, a whole variety of products normally processed by solvent or detergent fractionation can now be obtained with a high degree of selectivity by dry fractionation. The original booming of the dry fractionation process has helped palm oil to conquer a strong position on the commodity market. Today, palm oil is without doubt the most widely fractionated oil. New demands for special cuts drifted the industry toward a more sophisticated approach with the production of higher cold stability oils (super- and topoleins), of vitamin enriched fractions (high carotene, tocopherol and tocotrienol contents) and of specialty fats (cocoa butter equivalents and substitutes).

Enzymatic interesterification (non specific) has lately received increasing interest as an alternative to partial hydrogenation for the production of low-trans hard fat suitable for shortenings and stick or tub-type margarines. In this context, palm stearin is a suitable alternative to improve tolerance to high temperature and for crystal morphology and stability, although blending with softer oils (including palm liquid fractions) remains necessary to impart plasticity to the final product. On the other side, specialty fats are widely used in food industry for applications where specific physical properties are important. Most confectionery products have a high fat content and meltdown in the mouth is extremely critical. The standard of excellence is cocoa butter and for this reason, specialty fats are often designed to have positive traits of cocoa butter or properties that make them more suitable for specific applications. Low-trans specialty fats can be developed from palm oil (or palm kernel oil) fractions. On the other hand, fat modification technologies like dry fractionation as such or eventually combined with 
specific enzymatic interesterification constitute a new interesting approach to design special new products.

\section{Quality parameters of crude palm oil}

Important aspects of the quality of crude palm oil have to be considered since they greatly affect the refining process. Chemical and physical properties have been determined from several surveys and currently incorporated in standards. The most important criteria to assess the quality of crude oil are acidity, oxidation parameters, DOBI, carotene content and the iron and cupper contents (table 1).

An acidity below $3 \%$ guarantees fresh fruits, good storage and controlled transportation; a freshly expelled crude palm oil, promptly dried and cooled, shows slow hydrolysis and oxidation; a high acidity is usually combined with high iron and copper levels, both having important pro-oxidant potential; low grade crude palm oil suffers auto-oxidation of carotene.

A good test to asses the quality of a crude palm oil is the deterioration of bleachability index, shortly said DOBI. The DOBI is basically the ratio between the content of carotenes and secondary oxidation products. The most easily refined palm oil has a DOBI above 2.5; a DOBI below 2 testifies an oil with very poor quality and more difficult to refine. A crude oil with a DOBI above 3 can be considered as an oil of very satisfactory quality. It's a matter of fact that good-quality refined oils can not be produced from low quality oils. A bleachability test was developed (table 2) to predict the final color of crude palm oil. Six crude palm oils with an initial acidity from 7.2 to $1.9 \%$ were prepared. The low DOBI values combined with elevated levels of fatty acids and peroxides gave the indication that some samples were difficult to bleach. Oils were bleached and steam refined and the final color of the heat bleached oils was observed. Conclusion was clear: a heat-bleached palm oil with color below $2 \mathrm{R}$ can only be produced when crude palm oil has a DOBI above 2.5.

\section{Palm oil refining}

Deodorization is a crucial stage of the refining process which has an important effect on final oil quality: organoleptic and stability characteristics, nutritional value and functional properties must be considered. The targets are bland taste and smell, low acidity and no hydrolysis, high oxidative stability, light and stable color and in some cases removal of contaminants.
Table 1. Specifications and quality requirements for crude palm oil.

\begin{tabular}{|llllllc|}
\hline & $\begin{array}{l}\text { Special } \\
\text { quality }\end{array}$ & $\begin{array}{l}\text { Standard } \\
\text { quality I }\end{array}$ & $\begin{array}{l}\text { Standard } \\
\text { quality II }\end{array}$ & $\begin{array}{l}\text { Special } \\
\text { grade }\end{array}$ & Lotox & Standard \\
\hline FFA (C16:0 \% max.) & 2.5 & 3.5 & 5.0 & 2.5 & 2.5 & 3.5 \\
Moisture and Impurities & 0.25 & 0.25 & 0.25 & - & - & - \\
(\% max.) & & & & & & \\
Moisture (\% max.) & - & - & - & 0.2 & 0.2 & 0.2 \\
Impurities (\% max.) & - & - & - & 0.02 & 0.02 & 0.02 \\
Peroxide value (meq & 2.0 & - & - & 3 & 3 & 5 \\
O /kg max.) & & & & & & \\
Anisidine value (max.) & 4.0 & - & - & 4 & 3.5 & - \\
DOBI (min.) & 2.8 & 2.5 & 2.2 & - & - & - \\
Carotene (ppm max.) & - & - & - & - & $600-700$ & - \\
Fe (ppm max.) & - & - & - & 4 & 4 & 5 \\
Cu (ppm max.) & - & - & - & 0.02 & 0.2 & 0.2 \\
\hline
\end{tabular}

Table 2. Influence of crude palm oil quality on the final color of physically refined palm oil $\left(260^{\circ} \mathrm{C} / 3 \mathrm{mbar} / 50 \mathrm{~min}\right.$.).

\begin{tabular}{|lllllll|}
\hline Crude palm oil: & $\begin{array}{l}\text { Bad } \\
\text { grade }\end{array}$ & $\begin{array}{l}\text { Poor } \\
\text { grade 1 }\end{array}$ & $\begin{array}{l}\text { Poor } \\
\text { grade 2 }\end{array}$ & $\begin{array}{l}\text { Poor } \\
\text { grade 3 }\end{array}$ & $\begin{array}{l}\text { Fair } \\
\text { grade }\end{array}$ & $\begin{array}{l}\text { Good } \\
\text { grade }\end{array}$ \\
\hline FFA (C16:0 \%) & 7.2 & 4.3 & 3.5 & 4.9 & 2.8 & 1.9 \\
DOBI & 1.3 & 1.8 & 2.0 & 2.2 & 2.7 & 3.1 \\
Peroxide Value $\left(\mathrm{meq} / \mathrm{kgO}_{2}\right)$ & 2.3 & 3.8 & 3.2 & 3.5 & 0.4 & 1.0 \\
\hline RBD palm oil: & & & & & & \\
\hline Lovibond $\left(5^{\prime \prime} 1 / 4\right)(\mathrm{R} / \mathrm{Y})$ & $3.1 / 33$ & $3.0 / 35$ & $2.2 / 20$ & $2.0 / 20$ & $1.3 / 15$ & $1.4 / 15$ \\
\hline
\end{tabular}

The unwanted side effects are the formation of trans fatty acids, polymerization, acyl-migration and degradation of natural vitamins and antioxidants. In the case of palm oil, it becomes clear that good-quality palm oils are made at the plantation and not in the factory. Quality of the fully refined oil is completely inseparable from the quality of the crude oil. The high acidity of crude palm oil places physical refining as the first option. The latest developments in refining technology have been driven by the increased attention to nutritional quality. Optimizing the deodorization conditions for a maximum retention of natural characteristics is important. Due
1) Moderate temperature - long time (stage 1) Mild deodorisation and moderate stripping - Deodorisation and de-acidification -

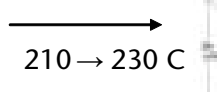

(1)

2) High temperature - short time (stage 2) Final stripping and heat bleaching - Controlled stripping of valuable minor components - Low transformation

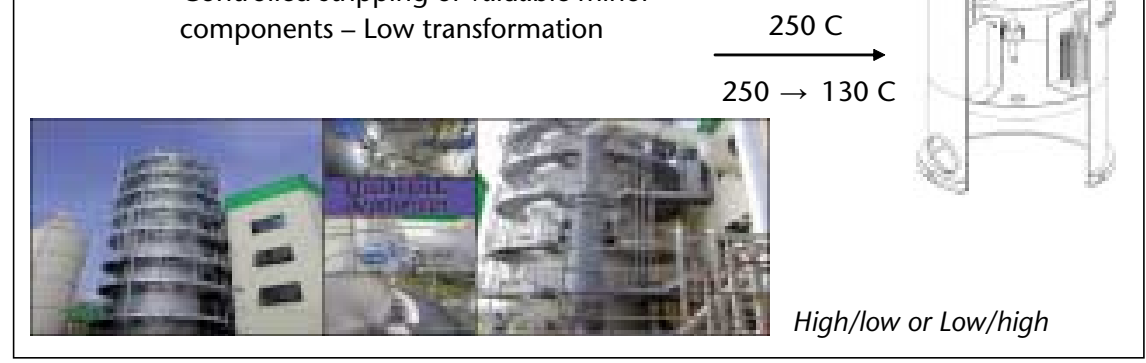

Figure 1. Principle of dual temperature deodorizer. 
to the market demand for minimizing trans fatty acids formation and improving tocopherol and tocotrienol retention, a dual temperature concept was developed. In the first step, the incoming oil is heated to moderate temperature after which it passes through the next deodorization trays. In these trays, de-acidification and deodorization take place under mild conditions (moderate temperature and moderate stripping). After the first trays, the oil passes a second heating tray in which it is heated to higher temperature. In the last trays, final stripping and heat bleaching occur. The process parameters can be adjusted to arrive at the desired tocopherol and tocotrienol level in the refined oil. The benefits also include low trans fatty acid formation because the time at high temperature is restricted (figure 1).

The free fatty acid content of a palm deodorizer distillate is usually $80-85 \%$ when the oil is refined according to the physical process. If two condensing units are introduced in the scrubber section, each of them set at an optimized temperature, two different distillates can be obtained with improved purity and added commercial value. With this double condensing system, the content of acylglycerols and other minor components in the condensed fatty acids is reduced and the free fatty acid purity is significantly improved (figure 2).

Normal deodorizers operate at 3-4 mbar. Today, special vacuum production units, ice condensing, have been developed to reach lower pressures (below 2 mbar) and at the same time to reduce emission and effluents by a more efficient condensation of the volatiles. The ice condensing system is becoming more and more the standard in new refining plants. In this system, the vapor is condensed on surface condensers working alternatively at very low temperature. The remaining non condensable matters are removed by mechanical pumps in series with liquid ring pump or by vacuum steam ejector system. The ice condensing system significantly reduces the motive steam consumption but also requires extra electrical energy (figure 3).

\section{Specially refined palm oil}

A golden palm oil rich in tocopherols, tocotrienols and carotenoid components is obtainable by physical refining. Dual temperature and low pressure (using ice condensing system) can be used to produce a physically refined palm oil with improved quality properties. This is the best option for a maximal retention of valuable minor components, for a good oxidative stability and an efficient removal of the free fatty acids (table 3).

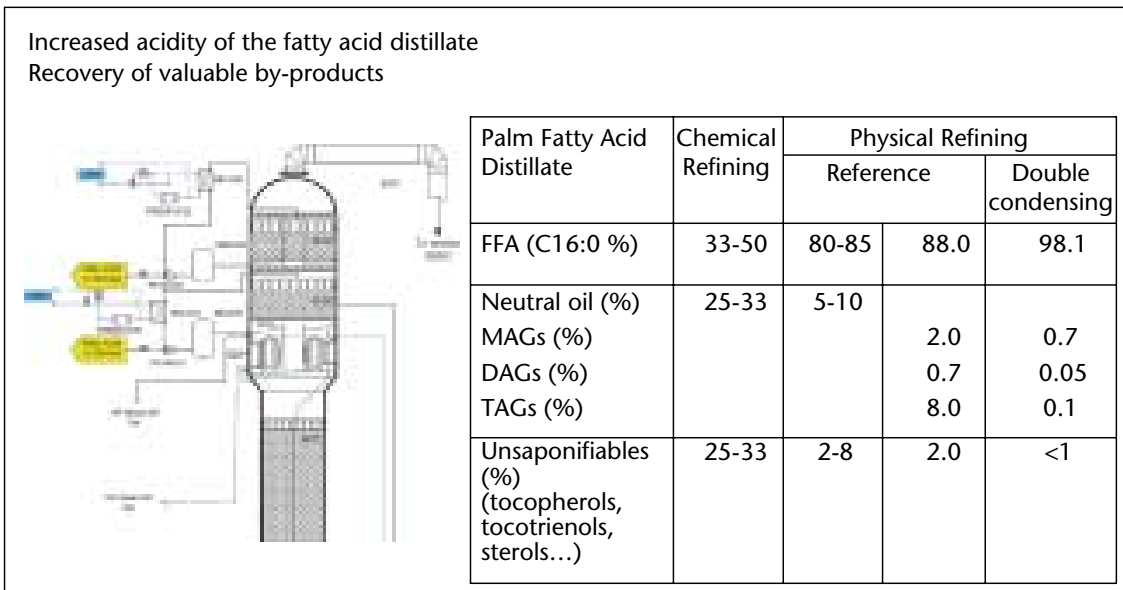

Figure 2. Quality parameters of palm fatty acid distillate (chemical refining and physical refining with and without double condensing unit). MAGs: monoacylglycerols; DAGs: diacylglycerols; TAGs: triacylglycerols.

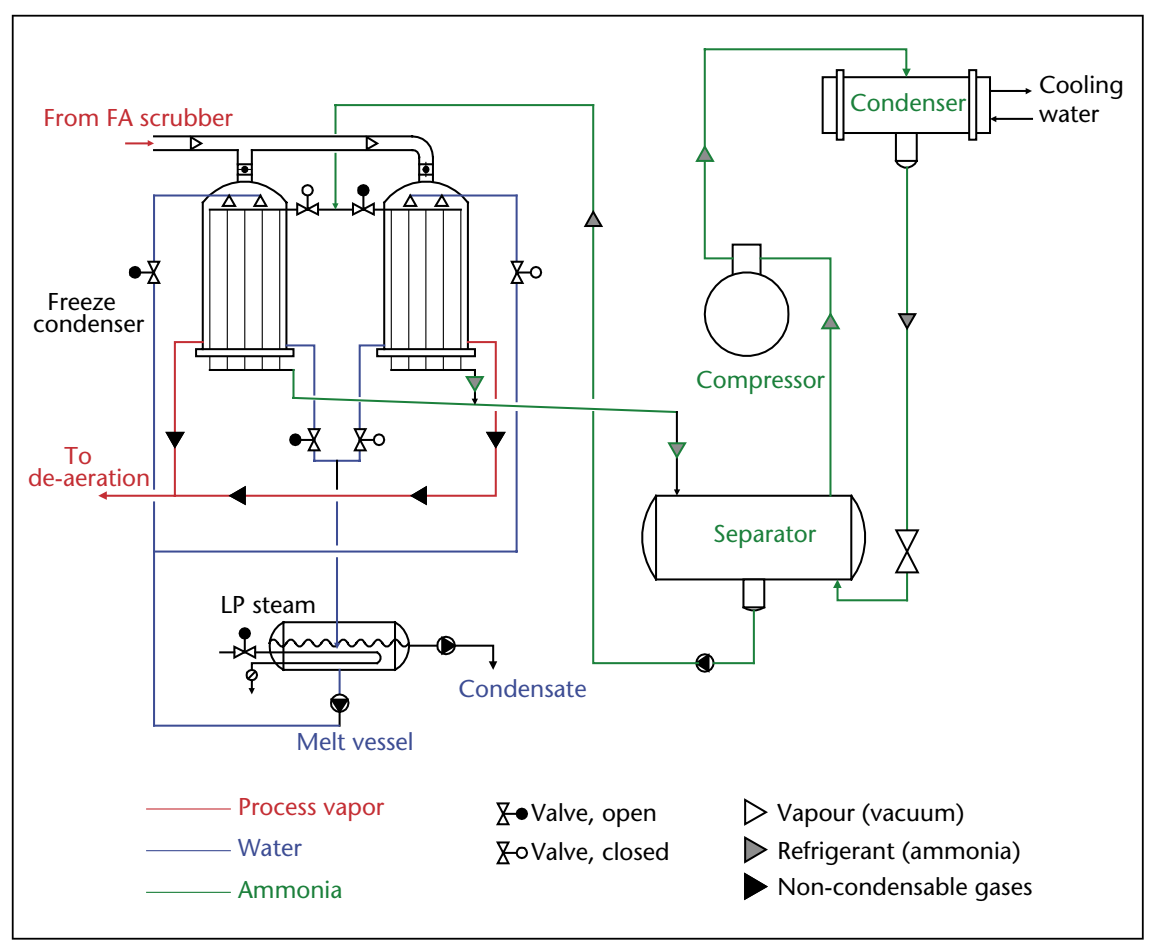

Figure 3. Principle of the dry (ice) condensing system.

Applied to very good quality crude palm oil (low acidity and high DOBI), a chemical refining plant is able to purify crude palm oil so efficiently that is can be deodorized directly (without bleaching) or in the worst case with very small amounts of nonactivated bleaching earths or silica. The thermal bleaching would only operate during deodorizing, resulting in reduced losses in tocopherols and tocotrienols and excellent oxidative stability for the final product. Thermal bleaching conducted at lower temperature is resulting in limited destruction of carotene together while keeping high amounts of tocopherols and tocotrienols in the oil (figure 4).

Production of white soaps from palm oil is not evident: the main problem is too dark color which is usually achieved due to the saponification step. Good results can only be expected when a crude palm oil of high quality is used and refining 
Table 3. Characteristics of Golden Palm Oil at different process conditions (physical refining).

\begin{tabular}{|lccccc|}
\hline & $\begin{array}{l}\text { RBD palm } \\
\text { oil } \\
\text { (reference) }\end{array}$ & $\begin{array}{l}\text { Golden } \\
\text { palm oil } \\
\text { A }\end{array}$ & $\begin{array}{l}\text { Golden } \\
\text { palm oil } \\
\text { B }\end{array}$ & $\begin{array}{l}\text { Golden } \\
\text { palm oil } \\
\text { C }\end{array}$ & $\begin{array}{l}\text { Golden } \\
\text { palm oil } \\
\text { D }\end{array}$ \\
\hline FFA (C16:0\%) & 0.07 & 0.20 & 0.07 & 0.08 & 0.07 \\
Lovibond $\left(5^{\prime \prime} 1 / 4\right)(\mathrm{R} / \mathrm{Y})$ & $2.5 / 25$ & $11.6 / 70$ & $6.2 / 50$ & $4.8 / 50$ & $4.1 / 42$ \\
Tocopherols/ & 544 & 709 & 671 & 629 & 699 \\
tocotrienols $(\mathrm{ppm})$ & & & & & 53.4 \\
OSI (hrs at $\left.97.8^{\circ} \mathrm{C}\right)$ & 70.5 & 61.5 & 63.0 & 50.6 & 53.4 \\
\hline
\end{tabular}

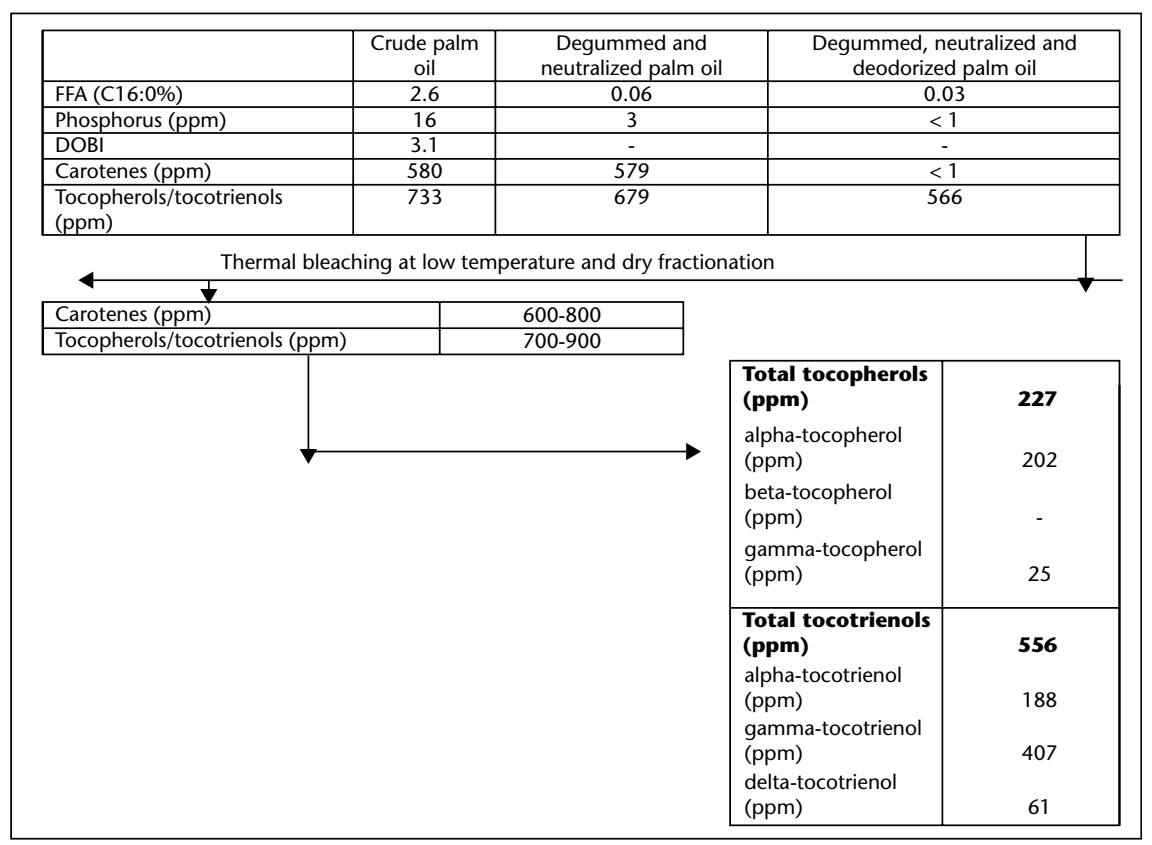

Figure 4. Characteristics of red palm oil specially refined and dry fractionated.

procedure performed under optimized conditions. Very good saponification colors (around 2.5R) can be obtained from a very light RBD palm oil that can be produced from crude oil having a DOBI above 3 (table 4).

\section{Dry fractionation of palm oil}

Today, palm oil is without doubt the most widely fractionated feedstock. Majority of better knowledge of fat crystallization properties and the design of new crystallizers (figure 5). Crystallization can be conducted slowly or faster; it's usually a batch or a semi-continuous process. High shear, low shear or static crystallization set-ups are possible for the best response to the demand of the fat industry. The crystallized material is further separated into a solid and a liquid fraction, typically with membrane press filters; last developments of this technology mainly refer to the use of bigger plates and higher squeezing pressures for better process economy and product quality improvement. The heterogeneous triacylglycerol composition of palm oil makes possible separation of compositionally distinct fractions, according to a multi-step process (figure 6).

Commodity oils (oleins, superoleins, stearins and soft palm mid fractions) are produced in one or two steps, main applications being ingredients for margarines or shortenings and frying or salad oils. The hard palm mid fraction (third step) is a specialty fat widely used in the confectionery industry as an ingredient for cocoa butter equivalent (CBE) formulation. Palm oil is indeed a valuable source of POP (2-oleo-diplamitin) and, at high POP levels, it becomes (after fractionation) suitable for cocoa butter replacement fats. The content of POP in the hard palm mid fraction is significantly increased during the multi-step dry fractionation process; final enrichment in the fraction can easily exceed $65 \%$ of POP (table 5). This specific composition offers to the hard palm mid fraction a very steep melting profile similar to the one of cocoa butter for specialty fats applications (figure 7). Specialty fats are indeed widely used in food industry for applications where specific physical properties are important. They are used in combination with other ingredients such as cocoa powder, sugar flavors, milk products, nuts... Most confectionery products have a high fat content and meltdown in the mouth is extremely critical. The standard of excellence is cocoa butter and for this reason, specialty fats are often designed to have positive traits of cocoa butter or properties that make them more suitable for specific applications. These

Table 4. Production of white soaps with low saponification color from physically refined palm oil (BE: bleaching earth; AC: activated carbon).

\begin{tabular}{|lll|}
\hline Crude palm oil (DOBI: $\mathbf{3 . 3}$ ) & & \\
\hline Refining conditions: & $\mathrm{RBD}$ oil color (R 5"1/4 Lovibond) & Saponification soap color (R 5"1/4 Lovibond) \\
Treatment with $1.5 \% \mathrm{BE}$ and deodorization at $280^{\circ} \mathrm{C}$ & 0.9 & 3.6 \\
Treatment with $1.5 \% \mathrm{BE}+0.4 \% \mathrm{AC}$ and deodorization at $280^{\circ} \mathrm{C}$ & 0.7 & 2.8 \\
Treatment with $2.5 \% \mathrm{BE}+0.5 \% \mathrm{AC}$ and deodorization at $280^{\circ} \mathrm{C}$ & 0.6 & 2.5 \\
\hline
\end{tabular}



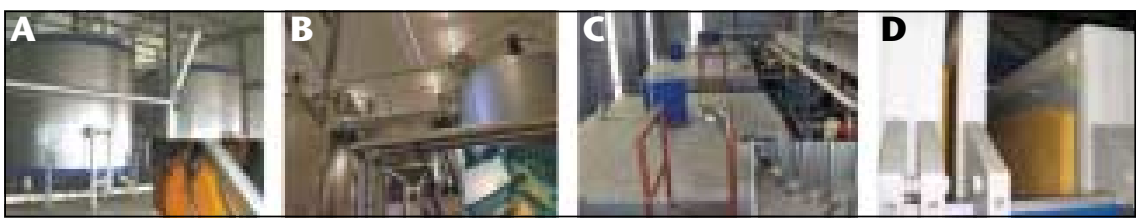

Figure 5. Crystallizers used for dry fractionation: A) concentric, B) Tirtiaux, C) Mobulizer ${ }^{\odot}$ and D) Statolizer ${ }^{\odot}$.

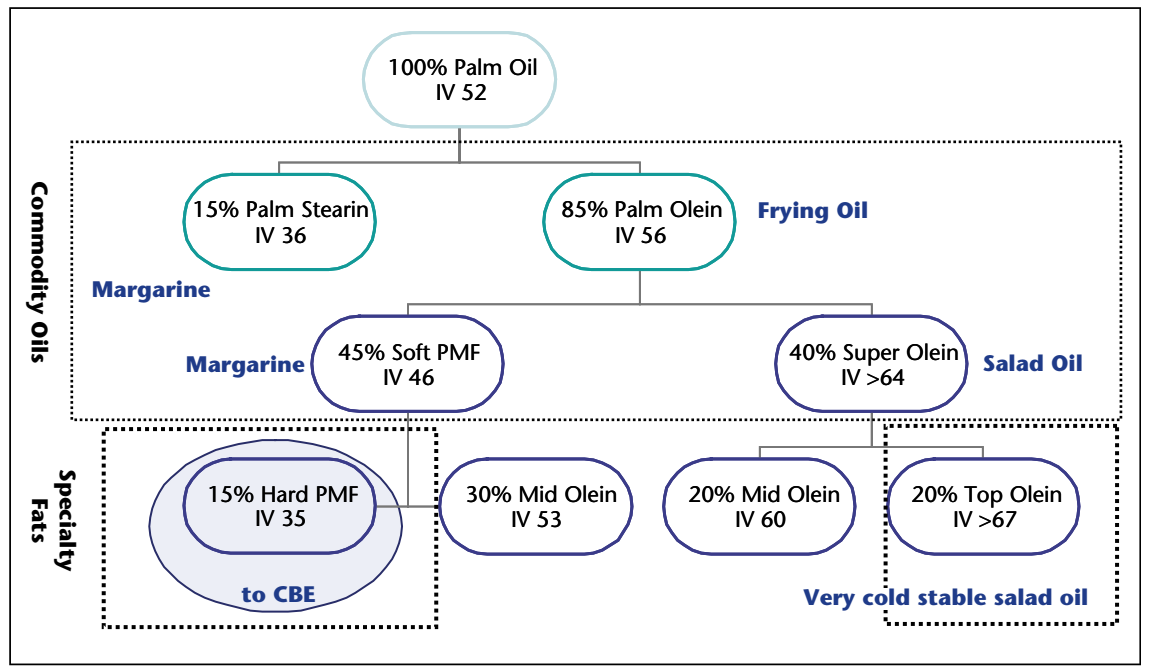

Figure 6. Multi-step dry fractionation of palm oil (for commodity oils and specialty fats).

include melting and solidification properties, fine crystal structure, snap, gloss, color and flavor release. Miscibility with cocoa butter is another important aspect that needs to be considered. A true cocoa butter equivalent
(CBE) is an all-vegetable non hydrogenated product (generally based on four raw materials: illipe, shea butter, sal fat and palm oil) containing almost the same fatty acids and acylglycerol present in a typical cocoa butter; as a result of the closely similar chemical composition, the physical properties of a CBE also closely match to cocoa butter. CBE are fully compatible with cocoa butter and can be used in any proportion up to $100 \%$ for complete replacement; they also require the same tempering procedures as cocoa butter to prevent fat bloom.

Cocoa butter substitutes (CBS) are principally made of palm kernel oil after fractionation. Palm kernel stearin is particularly enriched in lauric and myristic fatty acids and, for this reason, compatibility with cocoa butter is poor. Cocoa butter would not exceed $5 \%$ of CBS to avoid softening. The stearin by itself, or after full hydrogenation, is an excellent CBS, with a very high solid fat content at $20{ }^{\circ} \mathrm{C}$ making it a material of choice for molded products with good fat bloom resistance and good snap; there is no need for tempering as the formed crystals are stable. Cocoa butter replacers (CBR) are produced by hydrogenation of liquid oil, frequently followed by dry fractionation. Raw materials can include rapeseed, sunflower, soybean and also palm oil or palm olein. The fractionated CBR have better melting profile and better eating quality than the non fractionated ones but they are also more expensive. CBR can tolerate up to $25 \%$ of cocoa butter on fat base when used in confectionery coatings. It must be mentioned that today, the high trans content of CBR makes this alternative less desirable.

Table 5. Approximate concentration changes of the main triacylglycerol components during multi-step dry fractionation of palm oil (P: palmitic acid; S: stearic acid; O: oleic acid; L: linoleic acid; St: saturated acid; U: unsaturated acid).

\begin{tabular}{|c|c|c|c|c|}
\hline & & Step 1 & Step 2 & Step 3 \\
\hline $\begin{array}{l}\text { Acylglycerols } \\
\text { (w/w \% by HPLC) }\end{array}$ & $\begin{array}{l}\text { Palm oil } \\
\text { lodine value } 52\end{array}$ & $\begin{array}{l}\text { Palm olein } \\
\text { lodine value } 56\end{array}$ & $\begin{array}{l}\text { Soft palm mid fraction } \\
\text { lodine value } 46\end{array}$ & $\begin{array}{l}\text { Hard palm mid fraction } \\
\text { lodine value }<35\end{array}$ \\
\hline PPP & 5 & 0.5 & 0.2 & 0.4 \\
\hline POP & 29 & 29 & 49 & 67 \\
\hline POS & 5 & 5 & 9 & 12 \\
\hline SOS & 0.5 & 0.5 & 1 & 1.5 \\
\hline PLP & 10 & 10 & 10 & 6 \\
\hline POO & 21 & 23 & 13 & 5 \\
\hline SOO & 2.5 & 2.5 & 1.5 & 0.5 \\
\hline POL & 10 & 11 & 6 & 2 \\
\hline LOO & 2 & 2 & 1 & 0.2 \\
\hline 000 & 3 & 4 & 2 & 1 \\
\hline StStSt & 7 & 1 & 0.5 & 1 \\
\hline StUSt & 48 & 49 & 73 & 90 \\
\hline StUU & 39 & 43 & 23 & 8 \\
\hline UUU & 6 & 7 & 3.5 & 1 \\
\hline Diacylglycerols & 6 & 6 & 5 & 3 \\
\hline
\end{tabular}




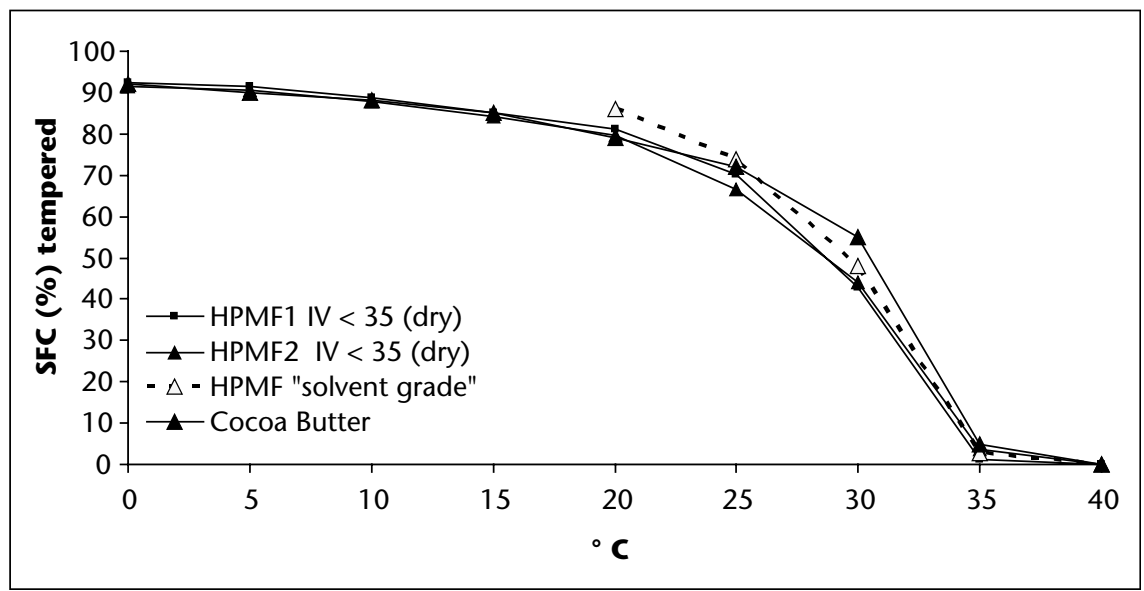

Figure 7. Solid fat content profile (IUPAC 2150 serial method with special tempering) of hard palm mid fractions (HPMF) produced by multi-step dry fractionation.

Table 6. Mettler cloud point of palm oleins IV 56 with increased diacylglycerol contents.

\begin{tabular}{|lcc|}
\hline Palm olein IV 56 & Diacylglycerol content $(\%)$ & Mettler cloud point $\left({ }^{\circ} \mathbf{C}\right)$ \\
\hline Olein 1 & 1.0 & 6.1 \\
Olein 2 & 3.0 & 6.5 \\
Olein 3 & 5.0 & 7.9 \\
Olein 4 & 7.0 & 9.1 \\
Olein 5 & 9.0 & 10.8 \\
Olein 6 & 11.0 & 12.0 \\
\hline
\end{tabular}

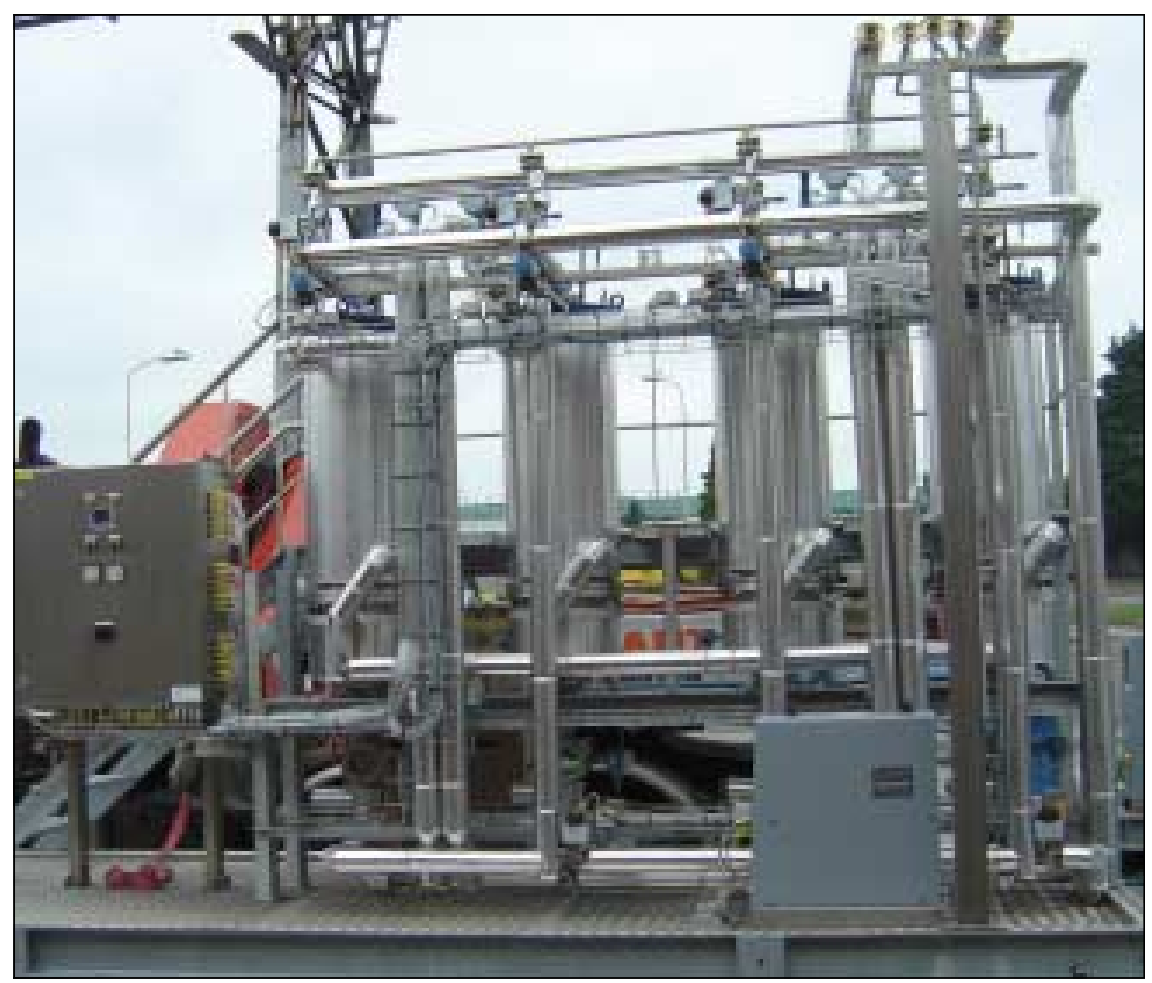

Figure 8. Enzymatic interesterification plant.
Dry fractionation is classically operated on refined palm oil but the high vitamin content of the crude oil makes the dry fractionation process (combined with special refining procedures) an attractive route for designing special (red) products: carotenes, tocopherols and tocotrienols concentrate markedly in the liquid fractions (oleins and superoleins) and quantities are still present in the solid fractions (stearins and palm mid fractions). A series of dedicated products (red palm superolein) are available on the market (figure 4).

Minor components like diacylglycerols, which can not be removed during the refining process of palm oil, have several disadvantages during dry fractionation; di- and triacylglycerols show eutectic interactions making separation difficult and fractionation incomplete. Also, high melting diacylglycerols (mainly 1,3-dipalmitoyl glycerol) develop cloudiness upon storage at room temperature affecting the cold resistance and the cloud point of the olein fractions (table 6). Finally, diacylglycerols have detrimental effect on crystallization performances of the speciality fats (CBE) and for this reason they need to be kept as low as possible during the whole dry fractionation process. Good quality crude palm oil (low acidity, high DOBI, good oxidative sate) is therefore mandatory as highly affecting the quality parameters of the palm fractions.

\section{Enzymatic interesterification}

Low trans margarines and shortenings are more and more formulated from fats modified with the interesterification process (chemical or enzymatic). Palm oil and its fractions are good candidates for this application. Non specific enzymatic interesterification is a random process (similar to chemical interesterification) offering better quality and improved oxidative stability to the final product. It's basically a continuous process used in fixed bed configuration. Cross contamination is low and the interesterified oil doesn't need to be post-bleached with consequently less oil losses. Practically, a blend of liquid oil and hard fat (most of the time fractionated) is continuously passing through the enzymatic fixed bed; interesterified oil serves as base stock for finished margarine and shortening fats (figure 8). Table 7 is presenting quality parameters and thermal characteristics of a blend of palm stearin and soybean oil (70\%/30\% w/w) submitted to chemical and non specific enzymatic interesterification. While thermal characteristics and triacylglycerol composition are similar for chemically and enzymatically interesterified oils, quality 
Table 7. Quality parameters and thermal characteristics of a palm stearin and soybean oil blend (70\%/30\% w/w) submitted to chemical and non specific enzymatic interesterification (Lipozyme TL IM - Novozymes) (Random: theoretical prediction based on the law of probability. P: palmitic acid; S: stearic acid; O: oleic acid; L: linoleic acid; Ln: linolenic).

\begin{tabular}{|c|c|c|c|c|c|c|}
\hline & $\begin{array}{l}\text { Palm stearin/ } \\
\text { soybean oil } \\
(70 \% / 30 \% \mathrm{w} / \mathrm{w})\end{array}$ & Random & $\begin{array}{l}\text { Chemically } \\
\text { interesterified } \\
\text { and bleached }\end{array}$ & $\begin{array}{l}\text { Enzymatically } \\
\text { interesterified }\end{array}$ & $\begin{array}{l}\text { Chemically } \\
\text { interesterified, } \\
\text { bleached and } \\
\text { deodorized }\end{array}$ & $\begin{array}{l}\text { Enzymatically } \\
\text { interesterified } \\
\text { and deodorized }\end{array}$ \\
\hline FFA (C16:1 \%) & 0.02 & -- & 0.5 & 0.2 & $<0.05$ & $<0.05$ \\
\hline Color (Lovibond 5"1/4) (R/Y) & $2.4 / 24$ & - & $1.8 / 21$ & $2.5 / 20$ & $1.7 / 20$ & $2.2 / 20$ \\
\hline Trans fatty acids (\%) & 0.1 & - & 0.1 & 0.1 & 0.1 & 0.1 \\
\hline Tocopherols/tocotrienols (ppm) & 462 & - & 337 & 454 & 175 & 321 \\
\hline $\begin{array}{l}\text { Diacylglycerols } \\
\text { (\% by HPLC) }\end{array}$ & 3.6 & - & 5.1 & 3.6 & 4.9 & 3.6 \\
\hline \multicolumn{7}{|l|}{ Triacylglycerols (w/w\% by HPLC) } \\
\hline $\operatorname{LnLL}$ & 2.3 & 0.2 & 0.3 & 0.3 & & \\
\hline LLL & 7.0 & 1.3 & 1.4 & 1.5 & & \\
\hline LLO & 5.6 & 2.9 & 3.2 & 3.2 & - & - \\
\hline LLP & 5.7 & 7.0 & 8.2 & 8.4 & & \\
\hline PPLn & 0.3 & 1.9 & 2.4 & 2.4 & & \\
\hline OLP & 7.9 & 14.1 & 15.1 & 15.4 & & \\
\hline PPL & 6.0 & 14.3 & 14.2 & 14.3 & & \\
\hline $\mathrm{OOO}$ & 2.4 & 3.0 & 1.7 & 1.7 & & \\
\hline POP & 20.8 & 17.4 & 18.9 & 18.8 & & \\
\hline PPP & 16.6 & 10.8 & 9.6 & 9.4 & & \\
\hline \multicolumn{7}{|l|}{$\begin{array}{l}\text { Solid Fat Content profile }\left(\% \text { at }{ }^{\circ} \mathrm{C}\right) \\
\text { (IUPAC } 2150 \text { serial non tempered) }\end{array}$} \\
\hline 0 & 57.0 & & 60.4 & 57.8 & 62.0 & 61.0 \\
\hline 10 & 57.1 & & 61.3 & 60.8 & 63.0 & 62.8 \\
\hline 20 & 45.2 & - & 41.6 & 42.8 & 42.9 & 43.3 \\
\hline 30 & 31.2 & & 21.6 & 22.7 & 22.4 & 23.0 \\
\hline 40 & 19.7 & & 10.7 & 10.3 & 10.7 & 10.7 \\
\hline 50 & 6.2 & & 0.0 & 0.0 & 0.0 & 0.0 \\
\hline
\end{tabular}

Table 8. Composition of hard palm mid fraction based CBE (P: palmitic acid; S: stearic acid; O: oleic acid).

\begin{tabular}{|lccc|}
\hline $\begin{array}{l}\text { Triacylglycerol content } \\
\text { (w/w \% by HPLC) }\end{array}$ & SOS & POS & POP \\
\hline Cocoa Butter & 26 & 37 & 18 \\
$\begin{array}{l}\text { CBE1 (HPMF/Shea butter } \\
\text { stearin) }\end{array}$ & 48 & 14 & 38 \\
$\begin{array}{l}\text { CBE2 (HPMF/Shea butter } \\
\text { stearin/ Illipe) }\end{array}$ & 43 & 24 & 33 \\
$\begin{array}{l}\text { CBE3 (Hard PMF/Illipe) } \\
\text { CBE4 (Hard PMF/Illipe/Sal }\end{array}$ & 34 & 15 & 50 \\
Stearin) & 21 & 36 \\
\hline
\end{tabular}

parameters of the enzymatically processed one are better: there is no formation of partial acylglycerols and tocopherol/tocotrienol content is preserved.

On the contrary, a regio-selective enzyme is required for specific enzymatic interesterification; in this case, acyl exchange is exclusively operating at specific positions of the

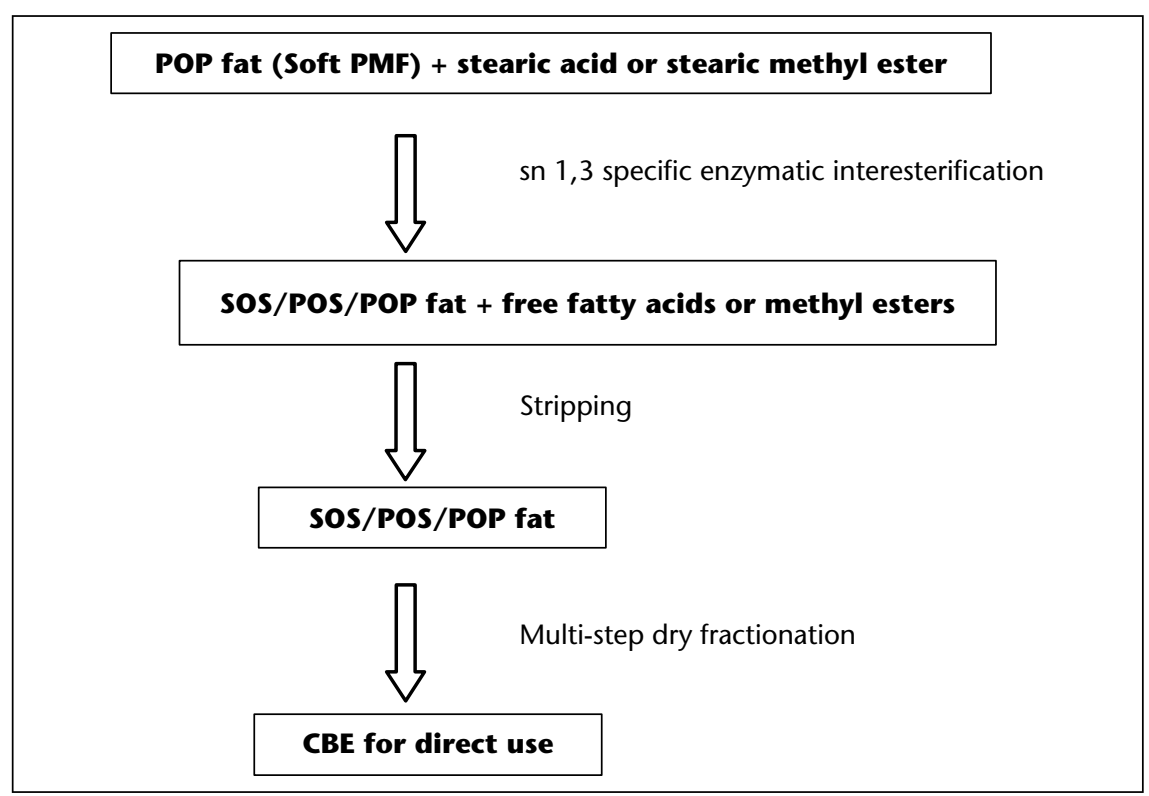

Figure 9. Example of CBE production by sn 1-3 specific enzymatic interesterification followed by multi-step dry fractionation (P: palmitic acid; S: stearic acid; O: oleic acid). 
glycerol backbone (most of the time at sn 1,3 positions). Specific enzymatic interesterification is mainly used for the production of specialty fats like low calorie or easily absorbable fats, infant formulation or CBE. When used in CBE formulation, the hard palm mid fraction is blended with other source to readjust the composition (table 8). To avoid this blending, cocoa butter equivalents can alternatively be produced by sn 1,3 selective enzymatic interesterification, idea being to preserve the unsaturated content at sn- 2 position while increasing the stearic content at sn 1-3 positions. Applied to palm oil, the strategy would be to modify a "POP fat" into a "POP/POS/SOS fat", as close as possible to the composition of cocoa butter (figure 9). Regio-selective enzymatic interesterification eventually followed by stripping of the acids or methyl esters in excess and dry fractionation for further enrichment makes possible compositional adjustment the main objective being a maximal achievable content in StUSt (SOS, POS and SOS) for use in confectionery.

\section{FURTHER READING}

Gibon V, De Greyt W, Kellens M. Palm Oil Refining. EJLST $2007 ; 109$ : 315-35.

Gibon V, De Greyt W, Kellens M. Palm Oil Fractionation. EJLST $2007 ; 109$ : 336-49.
De Greyt W, Kellens M. Deodorization. In : Shahidi F, ed. Bailey's Industrial Oil and Fat Products, Vol. 5. Hoboken, NJ (USA) : John Wiley and Sons, InC, 2005.

Calliauw G, Gibon V, De Greyt W, Plees L, Foubert I, Dewettinck K. Phase composition during palm olein fractionation and its effect on soft PMF and superolein quality. JAOCS $2007 ; 84$ : 885-91.

Costales-Rodrigez R, Gibon V, Verhe R, De Greyt $W$. Chemical and enzymatic interesterification of a blend of palm stearin/soybean oil for low-trans margarine formulation. JAOCS $2009 ; 86: 681-97$.

Wong SOO. Speciality Fats versus Cocoa Butter. Malaysia, 1991. 